\title{
Development of New Foaming Agent for Metal Foam
}

\author{
Takashi Nakamura ${ }^{1}$, Svyatoslav V. Gnyloskurenko ${ }^{1, * 1}$, Kazuhiro Sakamoto ${ }^{1, * 2}$, \\ Aleksandra V. Byakova ${ }^{2}{ }^{3}$ and Ryoichi Ishikawa ${ }^{3}$ \\ ${ }^{1}$ Institute of Multidisciplinary Research for Advanced Materials, Tohoku University, Sendai 980-8577, Japan \\ ${ }^{2}$ National Technical University of Ukraine Kiev Polytechnic Institute, 37 Prospect Peremohy, 04056, Kyiv, Ukraine \\ ${ }^{3}$ TOCHIGI R\&D CENTER Honda R\&D CO., LTD. Haga-machi Haga-gun Tochigi 321-3393, Japan
}

The study of metallic foams has become attractive to researchers interested in both scientific and industrial applications. The different production methods have not been widely utilized because of difficult process control and high production costs. A new easily-available agent for metal foaming, calcium carbonate, is suggested in this work. An established ion-exchange method was employed for a novel purposethe coating of calcium carbonate powder with fluoride for wettability enhancement. Effect of coating was considered by the examination of wetting behavior of coated and uncoated $\mathrm{CaCO}_{3}$ by the $\mathrm{Al}$ melt. It was determined that coated carbonate produced metallic foam with density comparable to that of samples treated by titanium hydride $\left(\sim 1 \times 10^{3} \mathrm{~kg} \cdot \mathrm{m}^{-3}\right)$ and much less then the density of samples obtained by uncoated carbonate $\left(1.7 \times 10^{3} \mathrm{~kg} \cdot \mathrm{m}^{-3}\right)$. It was also observed that coated carbonate ensured aluminum foam with smaller pores $\left(1.1 \times 10^{-3} \mathrm{~m}\right)$ than when the conventional foaming agent, titanium hydride, is used $\left(1.8 \times 10^{-3} \mathrm{~m}\right)$. The present study shows that calcium carbonate is highly applicable to foamed metal production.

(Received December 28, 2001; Accepted March 14, 2002)

Keywords: foamed aluminum, foaming agent, foam structure, calcium carbonate, coating, wettability, contact angle

\section{Introduction}

High-performance light-weight structures are becoming a dominant feature in automotive technology and in all fields where effective utilization of energy for motion of any kind is important. This means that metal foams with low density and high rigidity are of increasing interest. Apart from the reduction in weight, a number of other aspects such as comfort, safety and material recycling also have to be considered. Methods to produce metal foams are already known and classified. ${ }^{1,2)}$ Molten metal can be processed to a porous material by injecting gas into the melt ${ }^{3)}$ or by adding a foaming agent (FA) into it. ${ }^{4)}$ Two reasons why metal foams are not currently widely used are difficult process control and high production costs. From a technological viewpoint, a particular concern is the control of pore size, porosity level and the homogeneity of the foam. In order to meet the above requirements, a new easily available agent for metal foaming, calcium carbonate, is suggested instead of the conventional agent, titanium hydride. A homogeneous distribution of the powder agent in a melt can be achieved by enhancing the wetting of particles. This problem is usually solved by applying surface coating techniques used for different purposes such as in the production of metal matrix composite (MMC), ${ }^{5)}$ the bonding of ceramic components to metals, and in the manufacture of coated powders. $\left.{ }^{6}\right)$

In this work, the ion-exchange process was employed for the novel purpose of coating calcium carbonate powder with fluoride. The present study aims to investigate the coating procedure, to compare the foaming ability of the conventional FA $\left(\mathrm{TiH}_{2}\right)$ with the new one $\left(\mathrm{CaCO}_{3}\right)$, and to elucidate the impact of surface phenomena occurring during melt foaming

\footnotetext{
${ }^{* 1}$ Corresponding author: E-mail address: slava@iamp.tohoku.ac.jp

${ }^{* 2}$ Graduate Student, Tohoku University.

${ }^{* 3}$ Formerly: Visiting Professor, Institute of Multidisciplinary Research for Advanced Materials, Tohoku University, Sendai 980-8577, Japan.
}

on the structure of solid foam.

\section{Materials and Experimental Procedures}

\subsection{Powder coating technique and surface analysis}

A commercial calcium carbonate powder with particle size of $7.5 \mu \mathrm{m}$ was coated as follows. An aqueous solution containing $\mathrm{NaF}$ was prepared (Table 1). $11.5 \mathrm{~g}$ of calcium carbonate powder was added to $115.5 \mathrm{~mL}$ of the solution, and the solution was stirred for different fixed times (Table 1) at $40^{\circ} \mathrm{C}$ to induce the ion exchange reaction:

$$
\mathrm{CaCO}_{3}+2 \mathrm{NaF}=\mathrm{CaF}_{2}+\mathrm{Na}_{2} \mathrm{CO}_{3}
$$

Since the solubility of $\mathrm{CaCO}_{3}$ and $\mathrm{CaF}_{2}$ in water is relatively low (Table 2), these compounds exist in solution as solids, so that coating is possible. After stirring, the solution was filtered using a membrane filter with $1 \mu \mathrm{m}$ pores. The $\mathrm{CaCO}_{3}$ powder obtained was then dried in an oven at $120^{\circ} \mathrm{C}$

Table 1 Conditions for the coating experiments.

\begin{tabular}{lc}
\hline Parameter & Value \\
\hline Concentration of $\mathrm{NaF}$ solution $($ mass $\%)$ & 0.42 \\
$\mathrm{CaCO}_{3}$ powder/NaF solution $(\mathrm{g} / \mathrm{g})$ & 0.1 \\
Solution temperature $\left({ }^{\circ} \mathrm{C}\right)$ & 40 \\
Stirring rate $(\mathrm{rpm})$ & 200 \\
Stirring time $(\mathrm{min})$ & $10,30,60$ \\
\hline
\end{tabular}

Table 2 Solubility thresholds of the compounds in water.

\begin{tabular}{cc}
\hline Compound & Solubility, g/100g solution \\
\hline $\mathrm{CaCO}_{3}$ & $1.0 \times 10^{-3}$ \\
$\mathrm{Na}_{2} \mathrm{CO}_{3}$ & 22.7 \\
$\mathrm{CaF}_{2}$ & $1.8 \times 10^{-3}$ \\
$\mathrm{NaF}$ & 3.98 \\
\hline
\end{tabular}


for $12 \mathrm{~h}$. The experimental conditions for coating are shown in Table 1.

X-ray photoelectron spectroscopy (XPS) was used to study the chemical composition of the carbonate surface. These measurements were carried out using a PHI5600 ESCA spectrometer with a $\mathrm{Mg}-\mathrm{K} \alpha \mathrm{X}$-ray source operating at $400 \mathrm{~W}$. The anode potential was $14 \mathrm{kV}$. The energy scale was referenced to the well-defined carbon $1 \mathrm{~s}$ peak $(\mathrm{C} 1 \mathrm{~s})$, which has a binding energy of $284.5 \mathrm{eV}$. The powder used for XPS was applied to an indium plate at a uniform and complete coverage. XPS spectra of layers of increasing depth were obtained by Ar sputtering (acceleration voltage of $4.0 \mathrm{kV}$, sputtering area of $3 \mathrm{~mm}^{2}$ ).

Particle size and morphology of the powder were examined by scanning electron microscopy (SEM) (Hitachi S-4100L).

\subsection{Preparation of agents}

Instead of $\mathrm{CaCO}_{3}$ powder, a marble was used in the wetting study. Marble plates were cut into $6 \mathrm{~mm} \times 12 \mathrm{~mm}$ sections and polished with $1 \mu \mathrm{m}$ diamond slurry. The samples were coated with $\mathrm{CaF}_{2}$ by the technique described in Section 2.1 .

$\mathrm{TiH}_{2}$ powder with particle size of $10 \mu \mathrm{m}$ was compacted into cylindrical tablets $15 \mathrm{~mm}$ in height using a conventional pressurization technique. The tablets were then cut to obtain straight-edged sections of $6 \mathrm{~mm} \times 12 \mathrm{~mm}$.

\subsection{Wettability study}

The degree of wetting is usually estimated as the contact angle $(\theta)$ formed between a liquid and a solid surface in an atmosphere of gas. The dipping of a solid plate into a liquid metal was employed to study the wetting behavior of liquid $\mathrm{Al}$ in contact with solid foaming agents (Fig. 1). The contact angle was determined from an image contour of the junction of the three phases. If the contact angle is less than $90^{\circ}$, it can be optically measured since the liquid meniscus formed around the solid is above the horizontal liquid surface. However, because in the present study $\theta$ was grater than $90^{\circ}$, and because liquid metals are opaque, measurements of the contact angle necessitated the use of unconventional techniques, in this case X-ray observation.

The X-ray radioscopic visualization technique used in this study has been described in detail elsewhere. ${ }^{7,8)}$ In principle, when an X-ray beam with initial intensity of $I_{0}$ passes through

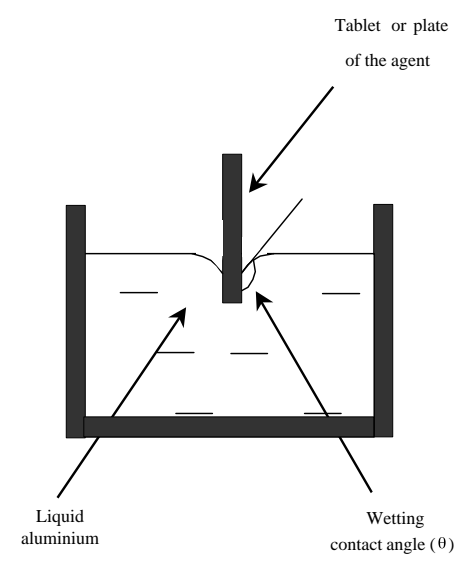

Fig. 1 Diagram showing contact angle $(\theta)$ between foaming agent and liquid metal. a material with thickness $d$ in the direction of the penetrating radiation, the output intensity $I$ is given by:

$$
I=I_{0} \exp \left((-\mu / \rho)_{0} \rho d\right)
$$

where $(\mu / \rho)_{0}$ is the reference mass attenuation coefficient and $\rho$ is the density of the material. A change in the surface profile or differences in the density of the target melt, caused for example by immersion of a solid plate of the different material in the melt, leads to a change in the intensity of X-ray beam emitted. Thus, the liquid meniscus formed around the solid plate due to the interfacial phenomenon can be clearly visualized.

A schematic view of the X-ray apparatus is shown in Fig. 2. An X-ray beam from a $150 \mathrm{kV}$ source used for general medical purposes (Hitachi Medical Corporation) was passed through a furnace and crucible filled with liquid aluminum. A fluorescent screen placed immediately behind the furnace was used to form an image, which was transmitted via an image intensifier to a CCD camera (XTV-S-420, Hitachi Medical Corporation). The X-ray system was used to observe and record events in the vicinity of the interface between solid plate, Al melt and furnace atmosphere. The output from the camera was displayed on a monitor and recorded either continuously onto videotape or periodically onto PC disk. Some high resolution images were also obtained using high intensity X-ray beams exposured to ordinary medical X-ray film. Selected images were transferred to a computer for image enhancement and measurement of the contact angles from the shape of the $\mathrm{Al}$ meniscus on the solid plate.

A $100 \mathrm{~g}$ sample of pure aluminium ( 99.9 mass $\%$ ) in grains was placed in an alumina crucible ( $36 \mathrm{~mm}$ i.d.) and melted in a resistance furnace in an inert (argon) atmosphere. Temperature of the melt and outside crucible wall was controlled by two Pt-Pt $16 \%$ Rh thermocouples. A solid plate of foaming agent was mounted by steel wire at the lower end of an $\mathrm{Al}_{2} \mathrm{O}_{3}$ tube, which was in turn fixed tigthly along the vertical central line of the alumina crucible. When the prescribed temperature $\left(690^{\circ} \mathrm{C}\right)$ was reached, the FA specimen was preheated and introduced vertically into the melt at low speed using an automatic device. When the meniscus profile became stable, further entry of the sample into the melt was stopped. Foaming agents were immersed to depths of 5-8 $\mathrm{mm}$. X-ray observation was carried out for $15 \mathrm{~min}$. The optimum condi-

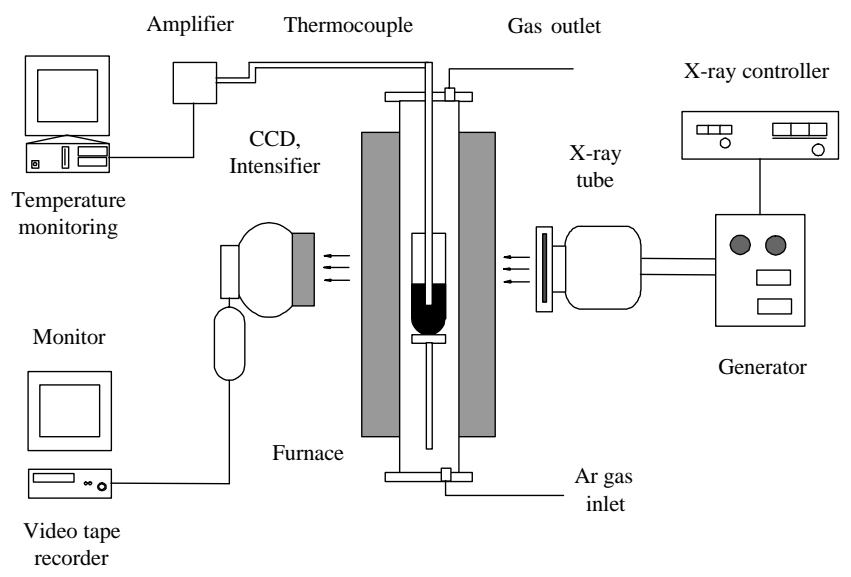

Fig. 2 Schematic view of the X-ray apparatus for studying wettability. 
tions for image generation in high intensity mode were found to be a $200 \mathrm{~mA}$ tube current at $150 \mathrm{kV}$ with an exposure time of $0.12 \mathrm{~s}$.

The experimental conditions for all foaming agents $\left(\mathrm{TiH}_{2}\right.$, coated and uncoated $\mathrm{CaCO}_{3}$ ) were identical.

\subsection{Foaming experiment}

An aluminium foaming by the conventional FA (titanium hydride) and the experimental calcium carbonates was carried out using a foaming route ALPORAS. ${ }^{4)}$ Special attention was given to distinguishing the behaviors of coated and uncoated carbonates. $500 \mathrm{~g}$ of an aluminium alloy (A 356) was placed in a stainless steel crucible $(100 \mathrm{~mm}$ i.d.) and melted in a resistance furnace. $\mathrm{Ca}$ as a thickening agent was added into the melt at $750^{\circ} \mathrm{C}$ while stirring in an ambient atmosphere. After temperature decreased to prescribed value (see Table 3 ), the molten aluminum was mixed with the foaming agent powder. The last then decomposed evolving gas and caused melt to foam. Finally, foam was cooled by fans. The samples were cut and measurements made of foam quality, including density and pores size. The experimental conditions are presented in Table 3.

\section{Results and Discussion}

\subsection{SEM and XPS surface analysis of foaming agent coating}

The morphology of calcium carbonate powder was examined by scanning electron microscopy (SEM). SEM micrographs of the uncoated and coated particles are shown in Fig. 3. All crystals were identical in shape. Discrete small particles were present on the surface of most crystals. The only difference in surface morphology of uncoated and coated particles was the presence of dissolution traces on the edges of the coated particles. It would appear that coating can not be detected by SEM.

The atomic spectrum of coated carbonate powder revealed by XPS analysis is shown in Fig. 4. All peaks are labeled in accordance with their corresponded elements. The F1s peak designates $\mathrm{F}$ bonded to $\mathrm{Ca}(\mathrm{F}-\mathrm{Ca})$. This peak occurred throughout a $10 \mathrm{~min}$ sputtering period, indicating the presence of calcium fluoride on the carbonate surface. The F1s peak was not detected on uncoated carbonate particles. The $\mathrm{Na}$ 1s peak revealed at the beginning of sputtering decreased greatly after $30 \mathrm{~s}$ of sputtering. This points to the fact that sodium compounds exist only in patches on the particle sur-

Table 3 Conditions for the foaming experiments.

\begin{tabular}{lcc}
\hline Foaming agents & $\mathrm{TiH}_{2}$ & $\mathrm{CaCO}_{3}$ \\
\hline Temperature of Ca introduction $\left({ }^{\circ} \mathrm{C}\right)$ & \multicolumn{2}{c}{750} \\
\hline Stirring time (min) & 5 & \\
Temperature of FA introduction $\left({ }^{\circ} \mathrm{C}\right)$ & 640 & 680 \\
Particle size $(\mu \mathrm{m})$ & 10 & 7.4 \\
FA quantity (mass $\%)$ & 1 & 1 \\
Stirring time (min) & 2 & 2 \\
Holding time (min) & 10 & 0 \\
Foaming temperature $\left({ }^{\circ} \mathrm{C}\right)$ & 640 & 705 \\
\hline
\end{tabular}

face. Probably this occurred due to precipitation during solution filtering at the powder coating stage.

The thickness of the calcium fluoride layer can be roughly calculated assuming that particles are of spherical shape, equal in size and uniformly coated by $\mathrm{CaF}_{2}$. Fluorine concentration in powder coated for different times was measured spectrophotometrically. The values for the calculations are presented in Table 4. Results show that the thickness of coating was in the order of $10 \mathrm{~nm}$ (Table 5).
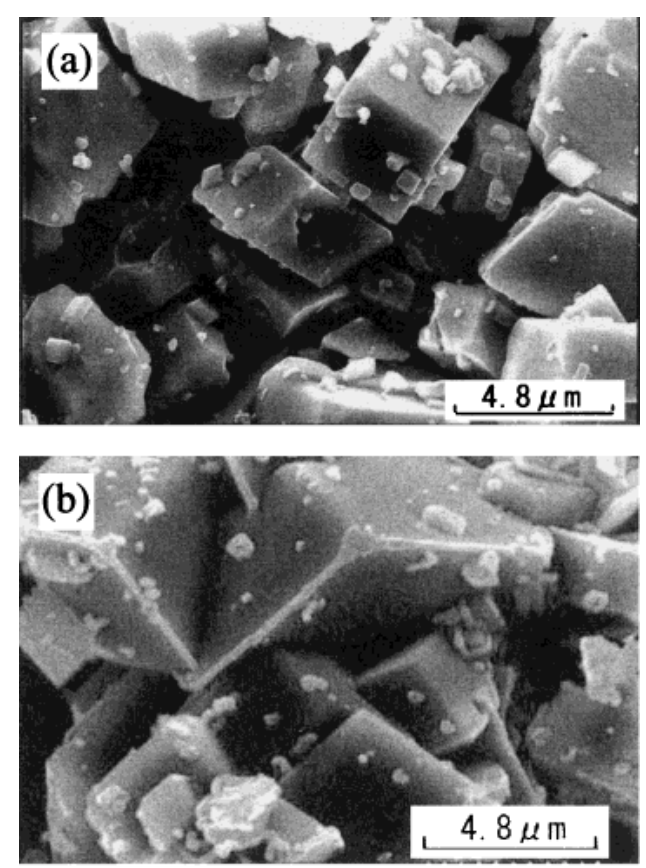

Fig. 3 SEM micrographs of $\mathrm{CaCO}_{3}$ powder (a) uncoated, (b) coated for $60 \mathrm{~min}$.

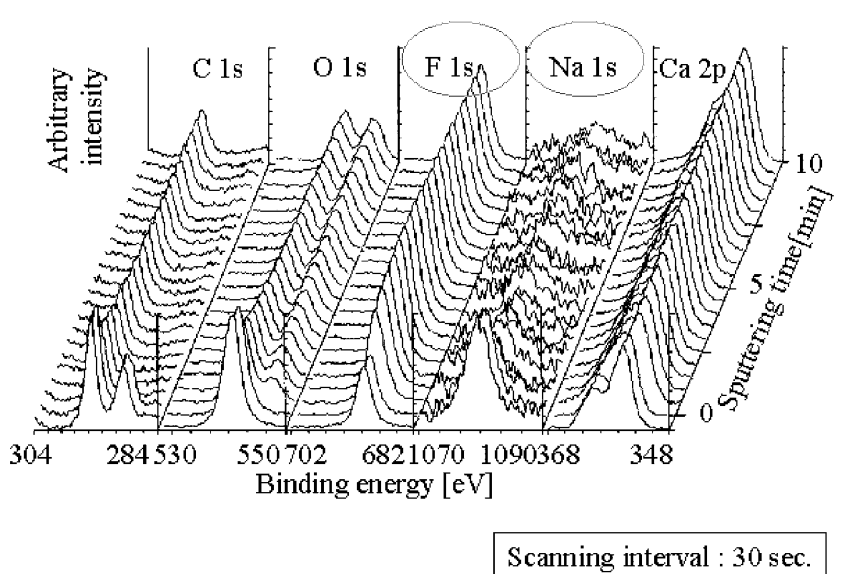

Fig. 4 XPS analysis of coated carbonate powder.

Table 4 Physical attributes of calcium compounds.

\begin{tabular}{lc}
\hline Parameter & Value \\
\hline Average particle diameter $(\mu \mathrm{m})$ & 7.4 \\
Density of $\mathrm{CaCO}_{3}\left(\mathrm{~kg} \cdot \mathrm{m}^{-3}\right)$ & 2700 \\
Density of $\mathrm{CaF}_{2}\left(\mathrm{~kg} \cdot \mathrm{m}^{-3}\right)$ & 3200 \\
\hline
\end{tabular}



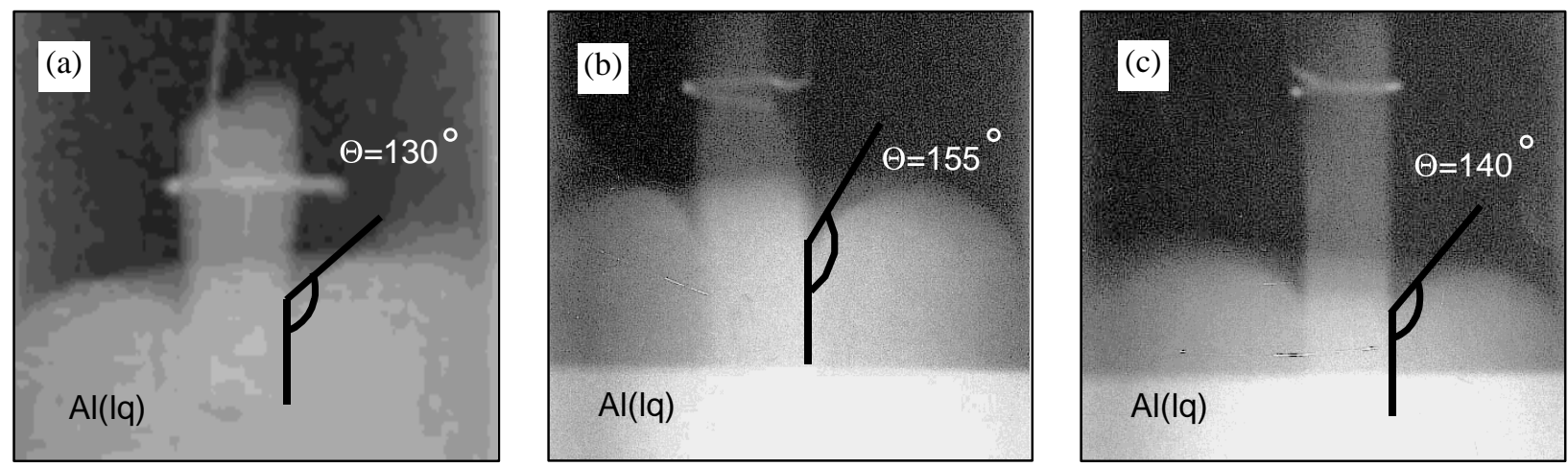

Fig. 5 X-ray images of surface profile after immersion of (a) titanium hydride tablet, (b) uncoated marble plate $\left(\mathrm{CaCO}_{3}\right)$ and $(\mathrm{c})$ coated marble plate in liquid aluminium. $\theta$ is the wetting contact angle.

Table 5 Fluorine concentration and coating thickness at different coating times.

\begin{tabular}{lccc}
\hline Parameter & \multicolumn{3}{c}{ Value } \\
\hline $\begin{array}{l}\text { Time of coating (min) } \\
\text { Concentration of }\end{array}$ & 10 & 30 & 60 \\
$\begin{array}{l}\text { fluorine (mass\%) } \\
\text { Thickness of the } \\
\text { coating layer }(\mathrm{nm})\end{array}$ & 1.09 & 1.22 & 1.43 \\
\hline
\end{tabular}

\subsection{Wettability study}

X-ray images obtained during several experimental series were processed and contact angles were measured.

It is $\mathrm{known}^{9)}$ that, as a solid is immersed, it contacts the liquid and a meniscus is progressively formed downwards (in the case of non-wetting) until the joining angle is equal to the immersion contact angle. At the same time, any deeper immersion of the solid does not give rise to any further change in the meniscus shape or in the contact angle. During the emersion of the solid, the joining angle changes continuously until emersion contact angle is reached. In the present study, only immersion contact angles were measured.

$\mathrm{X}$-ray observation of the interface between the three phases boundary was carried out for $15 \mathrm{~min}$. No changes in surface profile were observed within this period. The most typical pictures obtained within $5 \mathrm{~s}$ after immersion of a solid are presented in Fig. 5. Marble plate (Fig. 5(c)) was coated for $60 \mathrm{~min}$. Analysis of these data revealed some differences in the contact angles for different foaming agents. Titanium hydride formed a lower contact angle $\left(130^{\circ} \mathrm{C}\right) \mathrm{com}-$ pared with calcium carbonates, and coated $\mathrm{CaCO}_{3}$ resulted in a contact angle $15^{\circ}$ less than that formed by uncoated $\mathrm{CaCO}_{3}$ $\left(\theta \approx 140^{\circ}\right.$ and $155^{\circ}$, respectively). These observations confirm our expectations that the surface properties of the coated carbonates promote better wetting by the melt.

Mention should be made of some phenomena that are of great importance during wetting studies. Liquid aluminum readily reacts with oxygen in air to form solid aluminum oxide. This layer of solid alumina covers the melt surface and is known to interfere with wetting. ${ }^{10-12)}$ The wetting properties of liquid aluminum depend on the thickness of the oxidized layer. However, even a very thin layer is sufficient to alter $\theta$. To protect a melt surface and to ensure a proper examination of the contact zone between phases, ultrahigh vacuum appa- ratuses, high purity gases or appropriate atmospheres are usually applied. The equipment used in the present study could not ensure these requirements. Therefore, it is likely that a solid alumina layer covered the melt surface so that the wetting data correspond to the metal oxide, rather than to the pure liquid metal. Another important point concerns differences in the solid surface roughness that may introduce errors into the measurements. Finally it should be mentioned that thermal decomposition of the foaming agents started shortly after the solid plates had been introduced into the melt. Gas evolution can interfere with the stability of the interface between phases, which also may alter $\theta$. It seems that little information about the wettability of foaming agents by metallic melts is available in the literature due to this last problem.

These and other factors make it difficult to quantify precisely the wetting angles between pure aluminum and the solid from this type of experiment. Nevertheless, a comparative analysis of wetting behavior for different foaming agents and molten aluminum (covered with an oxidized layer of the same thickness) can be made. This is especially true for comparison of the wetting behavior of calcium carbonates and so for evaluation of the role of coating.

\subsection{Foaming experiments}

The influence of surface coating on foaming ability of the agents was also examined. The sectional views of the samples after foaming and cooling are presented in Fig. 6. All products were composed of two layers, a foamed layer on the upper part and a non-foamed bulk layer on the lower part. It is apparent that the coated agent (Fig. 6(c)) ensured a larger foamed fraction than the uncoated one (Fig. 6(b)), resulting in an increase in sample height and a decrease in total sample density (Fig. 7) $\left(1.0 \times 10^{3} \mathrm{~kg} \cdot \mathrm{m}^{-3}\right.$ compared with $\left.1.7 \times 10^{3} \mathrm{~kg} \cdot \mathrm{m}^{-3}\right)$. These results can be explained by the contribution made by agent coating.

It is known that solid particles with poor wettability tend to coagulate in a liquid. In contrast, wetted particles can be well distributed in a liquid without formation of large aggregates. If the solid is the source of a gas, the first occurrence results in fewer bubble nucleation centers in a liquid than the second one does. Consequently the liquid fraction containing bubbles is larger when the second occurrence is operating. Moreover, particles with good wettability can evolve gas easily in comparison with ones with poor wettability. It is likely 


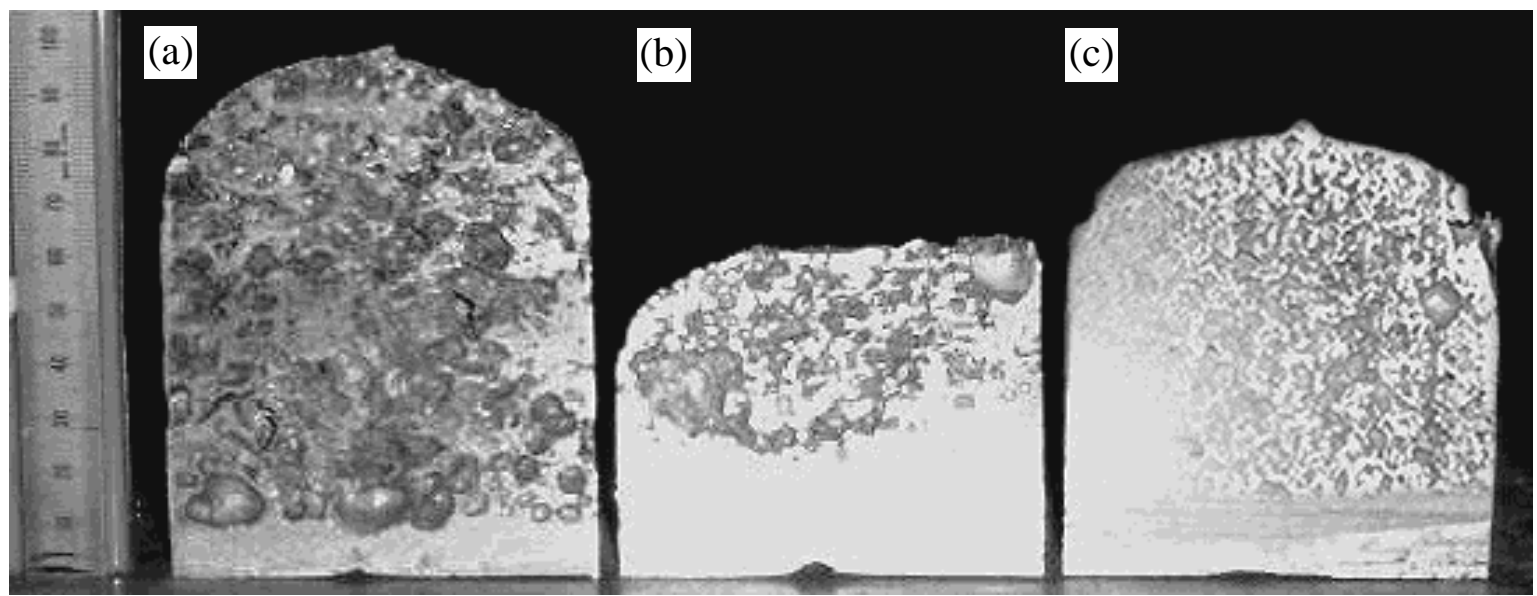

Fig. 6 Cross-section of the foamed aluminum samples treated with (a) titanium hydride, (b) uncoated $\mathrm{CaCO}_{3}$ and (c) coated $\mathrm{CaCO}_{3}$.

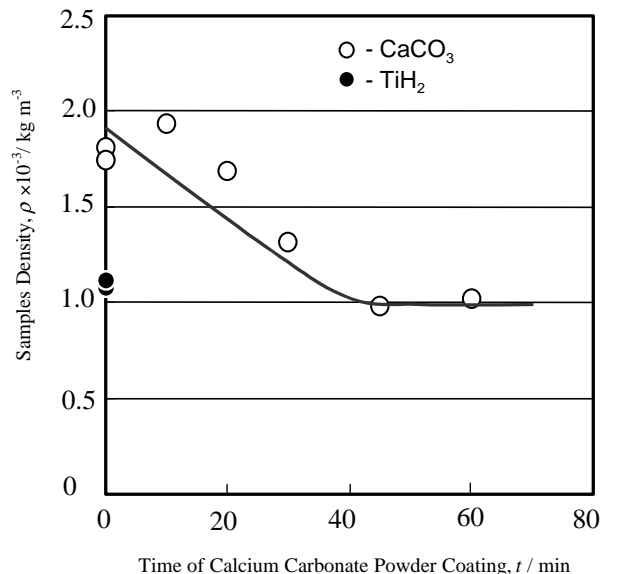

Fig. 7 Dependence of the foamed samples density on powder coating time for different foaming agents.

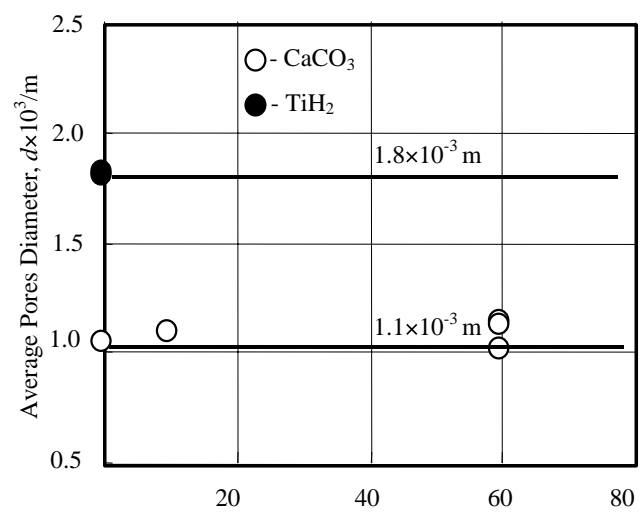

Time of Calcium Carbonate Powder Coating, $t / \mathrm{min}$

Fig. 8 Dependence of pores size of the foamed samples on powder coating time for different foaming agents.

that in our experiments the particles of coated carbonate were distributed in the melt more uniformly than uncoated one did and produced more foamy melt with lower density.

Most important for practical use of the new foaming agents is that coated carbonates produced metallic foam with a density comparable to that of samples treated by titanium hydride $\left(\sim 1.0 \times 10^{3} \mathrm{~kg} \cdot \mathrm{m}^{-3}\right)($ Fig. 7$)$ and with pores (cell size $=$ $1.1 \times 10^{-3} \mathrm{~m}$ ) smaller than those produced by conventional hydrides $\left(1.8 \times 10^{-3} \mathrm{~m}\right)$ (Fig. 8$)$. It was also determined that a coating period of $40 \mathrm{~min}$ is optimum to reduce foam density.

\section{Conclusion}

Calcium carbonate coating was prepared by an ion exchange method. A comparative study of the coated and uncoated $\mathrm{CaCO}_{3}$ was carried out by surface analysis of the particles. The presence of fluoride on the particle surface was revealed. Effect of coating was considered by the examination of wetting behavior of coated and uncoated $\mathrm{CaCO}_{3}$ by the $\mathrm{Al}$ melt. It was determined that coating of $\mathrm{CaCO}_{3}$ by the $\mathrm{CaF}_{2}$ resulted in a decrease in contact angle $\left(\sim 15^{\circ}\right)$ in comparison with uncoated carbonate. The possibility of using calcium carbonate as a new foaming agent for aluminum was supported following examination of agent foaming ability. Coated carbonate produced metallic foam with a density comparable to that of samples treated by titanium hydride $\left(\sim 1.0 \times 10^{3} \mathrm{~kg} \cdot \mathrm{m}^{-3}\right)$ and much less then uncoated carbonate $\left(1.7 \times 10^{3} \mathrm{~kg} \cdot \mathrm{m}^{-3}\right)$. It is believed that this result was caused by wettability enhancement due to the agent coating. For practical use of the new foaming agent, it is important that coated carbonate ensures aluminum foam with smaller pores $\left(1.1 \times 10^{-3} \mathrm{~m}\right)$ than those produced by the conventional FA, titanium hydride $\left(1.8 \times 10^{-3} \mathrm{~m}\right)$. Optimal conditions for agent coating were determined. Carbonate coated for $40 \mathrm{~min}$ had an optimum impact on reducing foam density. The present study shows that calcium carbonate is highly applicable to foamed metal production.

\section{REFERENCES}

1) J. Banhart and J. Baumeister: MRS Symp. Proc. 521 (MRS, San Francisco, California, USA, 1998) pp. 121-132.

2) C. Körner and R. F. Singer: Metal Matrix Composites and Metallic foams (EUROMAT99), vol. 5, ed. by T. W. Clyne and F. Simancik (Weinheim, New York, Wiley-Vch, 2000) pp. 3-13.

3) I. Jin, L. D. Kenny and H. Sang: US Patent 5112697 (1992).

4) S. Akiyama, H. Ueno, K. Imagawa, A. Kitahara, S. Nagata, K. Morimoto, T. Nishikawa and M. Itoh: US Patent 4713277 (1987).

5) J. P. Rocher, J. M. Quenisset and R. Naslain: J. Mater. Sci. 24 (1989) 2697-2703.

6) S. Suda, S. Ishikawa, N. Wada and T. Umegaki: J. Mater. Sci. 35 (2000) 3023-3028.

7) R. E. Pool and J. N. Koster: Int. J. Heat Mass Tran. 37 (1994) 2583- 
2587.

8) J. N. Koster, T. Seidel and R. Derebail: J. Fluid Mech. 343 (1997) 2941.

9) I. Rivollet, D. Chatain and N. Eustathopoulos: J. Mater. Sci. 25 (1990) 3179-3185.

10) J. J. Bikermann: Physical Surfaces, (New York and London, Academic
Press, 1970).

11) B. Maruyama, E. V. Barbera and L. Rabenberg: Metal Matrix Composites: Processing and interfaces, ed. by R. K. Everett and R. J. Arsenault (New York, Academic Press, 1991) pp. 182-210.

12) V. Laurent, D. Chatain and N. Eustathopoulos: Mater. Sci. Eng. A135 (1991) 89-94. 